\title{
Frequency-selective Heteronuclear Correlation (FS-HETCOR) Experiments in Solid-State NMR
}

Zhengfeng Zhang ${ }^{1 *}$, Yongchao $\mathrm{Su}^{2}$, Jun Yang ${ }^{1,3 *}$

1. National Center for Magnetic Resonance in Wuhan, Key Laboratory of Magnetic Resonance in Biological Systems, State Key Laboratory of Magnetic Resonance and Atomic and Molecular Physics, Wuhan Institute of Physics and Mathematics, Innovation Academy for Precision Measurement Science and Technology, Chinese Academy of Sciences, Wuhan 430071, P. R. China.

2. College of Pharmacy, The University of Texas at Austin, Austin, TX 78712, USA

3. Wuhan National Laboratory for Optoelectronics, Huazhong University of Science and Technology, Wuhan 430074, P. R. China

To whom correspondence should be addressed:

zhangzf@wipm.ac.cn (Z.Zhang)

yangjun@wipm.ac.cn (J. Yang)

\section{Keywords}

Heteronuclear correlation (HETCOR), Frequency-selective, Dipolar recoupling, Magic-angle spinning (MAS), solid-state NMR

\begin{abstract}
Heteronuclear correlation (HETCOR) is critical to obtain structural information in solid-state nuclear magnetic resonance (NMR). We propose novel frequency-selective Heteronuclear correlation (FS-HETCOR) experiments to selectively enhance the inter-atomic correlations of interest. FS-HETCOR relies on heteronuclear selective phase-optimized recoupling (SPRx), which is frequency-selective in heteronuclear recouping without using selective pulses. Compared to regular HETCOR, FS-HETCOR selectively enhances the desired heteronuclear correlations by a factor of up to 5 and suppresses the unwanted ones to $10 \%$ as demonstrated in ${ }^{1} \mathrm{H}-{ }^{19} \mathrm{~F}$ and ${ }^{1} \mathrm{H}^{13} \mathrm{C}$ experiments under fast magic-angle spinning (MAS). Moreover, FS-HETCOR can theoretically be applied at arbitrary MAS rates by utilizing various SPRx schemes. We believe that the method will enhance the ability of solid-state NMR to probe heteronuclear structural information.
\end{abstract}

\section{Introduction}

Heteronuclear correlation (HETCOR) experiments play critical roles to obtain structural 
information in nuclear magnetic resonance (NMR). ${ }^{1-5}$ Solid-state NMR often resorts to dipolar couplings that are 1-2 order of magnitude larger than scalar coupling to establish heteronuclear correlations. While magic-angle spinning (MAS) for line narrowing attenuates heteronuclear dipolar couplings, recoupling sequences are introduced to recover them for distance information. ${ }^{6-17}$ Cross polarization (CP) is the most-widely utilized technique to establish ${ }^{1} \mathrm{H}$-X or X-Y HETCOR experiments $\left(\mathrm{X}, \mathrm{Y}={ }^{13} \mathrm{C},{ }^{15} \mathrm{~N},{ }^{19} \mathrm{~F},{ }^{31} \mathrm{P}\right.$, etc) in studies of proteins, catalysts, polymers, and pharmaceuticals. ${ }^{18-25}$ However, most dipolar recoupling sequences often suffer from dipolar truncation ${ }^{26}$, preferentially establishing correlations of strongly coupled nuclei. The correlations from distant nuclei are typically truncated and therefore difficult to be observed.

Frequency-selective homonuclear ${ }^{1} \mathrm{H}-{ }^{1} \mathrm{H}$ or ${ }^{13} \mathrm{C}-{ }^{13} \mathrm{C}$ correlations have been observed via selective phase-optimized recoupling $(\mathrm{SPR})^{27-28}$ and other pulse schemes ${ }^{29-31}$. They can provide considerable enhancements of the desired correlations as the polarization is deliberately transferred to a small population of nuclei with distinct resonance frequencies. Similarly, selectively-enhanced HETCOR may also be achieved via frequency-selective heteronuclear recoupling. However, to our best knowledge, current frequency-selective heteronuclear techniques are mostly applied to selective distance measurements ${ }^{32-36}$, which rely heavily on selective pulses ${ }^{37-41}$. There is no known frequency-selective heteronuclear recoupling without using any selective pulses.

\section{Methods}

In this study, we propose a novel frequency-selective heteronuclear correlation (FS-HETCOR) experiment by employing heteronuclear selective phase-optimized recoupling (donated as SPRx). FS-HETCOR is designed to selectively observe and enhance the heteronuclear correlations of interest. Figure 1 shows the pulse sequences of SPRx- $N_{n}$ (a) and corresponding FS-HETCOR experiments $(b, c)$. SPRx is constructed by the unit of SPR that has been used for homonuclear recoupling ${ }^{27}$, following the idea of our previous dual back-to-back pulses (DBP) ${ }^{14-15}$. The basic phases or super-cycled phases of SPRx- $N_{n}$ are different on the two channels (see supplementary material).

Herein we demonstrate the usage of SPRx $-4_{1}$ and SPRx $-4_{3}$, which require the $v_{1} / v_{\mathrm{R}}$ ratios to be 2 and 0.75 , respectively ( $v_{1}$ is the RF amplitude and $v_{\mathrm{R}}$ is the MAS rate). The details in SPRx $-4_{1}$ and SPRx $-4_{3}$ are given in Table S1. For SPRx $-4_{1}$, the overall phases are $(02132031$ $203102131320310231021320) \times 90^{\circ}$ and $(02020202202020201313131331313131) \times 90^{\circ}$ on channels ${ }^{1} \mathrm{H}$ and S, respectively. For SPRx-4, the overall phases are (02132031 20310213 $1320310231021320) \times 90^{\circ}$ and $(02020202202020201313131331313131) \times 90^{\circ}$ on channels ${ }^{1} \mathrm{H}$ and S, respectively. Various SPRx $-N_{n}$ schemes would exist for arbitrary MAS rates, similar to SPR that have been used under from slow to ultrafast MAS ${ }^{27-28}$. 
(a) SPRx-Nn (2N $90^{\circ}$ pulses) SPR

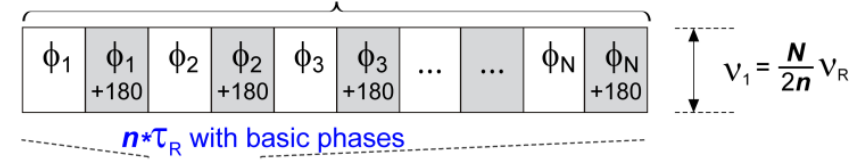
$n * \tau_{R}$ with basic phases

\begin{tabular}{|c|c|c|c|c|c|}
\hline \multirow{3}{*}{ SPRx- $N_{n}$} & ${ }^{1} \mathrm{H}$ & SPR & SPR & SPR & SPR \\
\hline & & & & & 'סחת \\
\hline & S & SPR' & SPR' & SPR' & SPR' \\
\hline
\end{tabular}

(b) FS-HETCOR

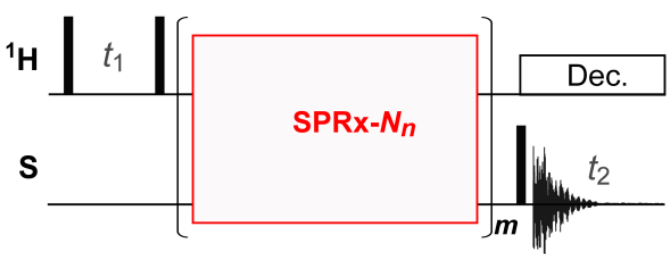

(c) ${ }^{1} \mathrm{H}$-detected FS-HETCOR

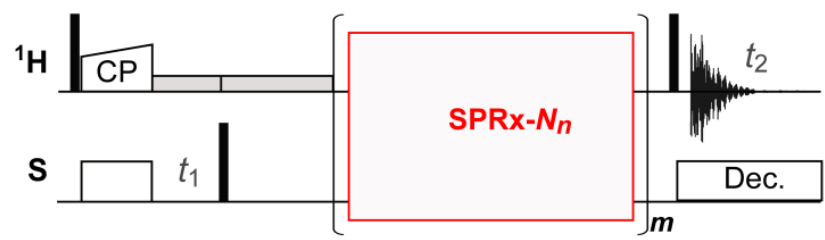

Figure 1 Pulse sequences of SPRx- $N_{n}$ (a) and corresponding FS-HETCOR experiments (b, c). Original SPR- $N_{n}$ consists of a block with $N$ pairs of " $90^{\circ}{ }_{\phi_{k}} 90^{\circ} \overline{\phi_{k}}$ " and a repeated block with a $180^{\circ}$ phase shift, where $\phi_{\mathrm{k}}$ represents the RF phase. ${ }^{27}$ (a) The SPR unit with a length of $n \tau_{\mathrm{R}}$ and basic phases is super-cycled to construct the heteronuclear SPR (SPRx), where $\tau_{\mathrm{R}}$ is the MAS rotor period. The basic phases or super-cycled phases are different on the two channels ( ${ }^{1} \mathrm{H}$ and S). (b) In FS-HETCOR, SPRx- $N_{n}$ is used for selective polarization transfer. Saturation pulses can be applied before the SPRx- $N_{n}$ block on Channel S to suppress the unwanted signals. (c) The ${ }^{1} \mathrm{H}$-detected FS-HETCOR is similar to CP-based heteronuclear single-quantum correlation (CP-HSQC) ${ }^{42-46}$ but uses the SPRx block for selective $\mathrm{S} \rightarrow{ }^{1} \mathrm{H}$ polarization transfer. 


\section{Results and discussion}
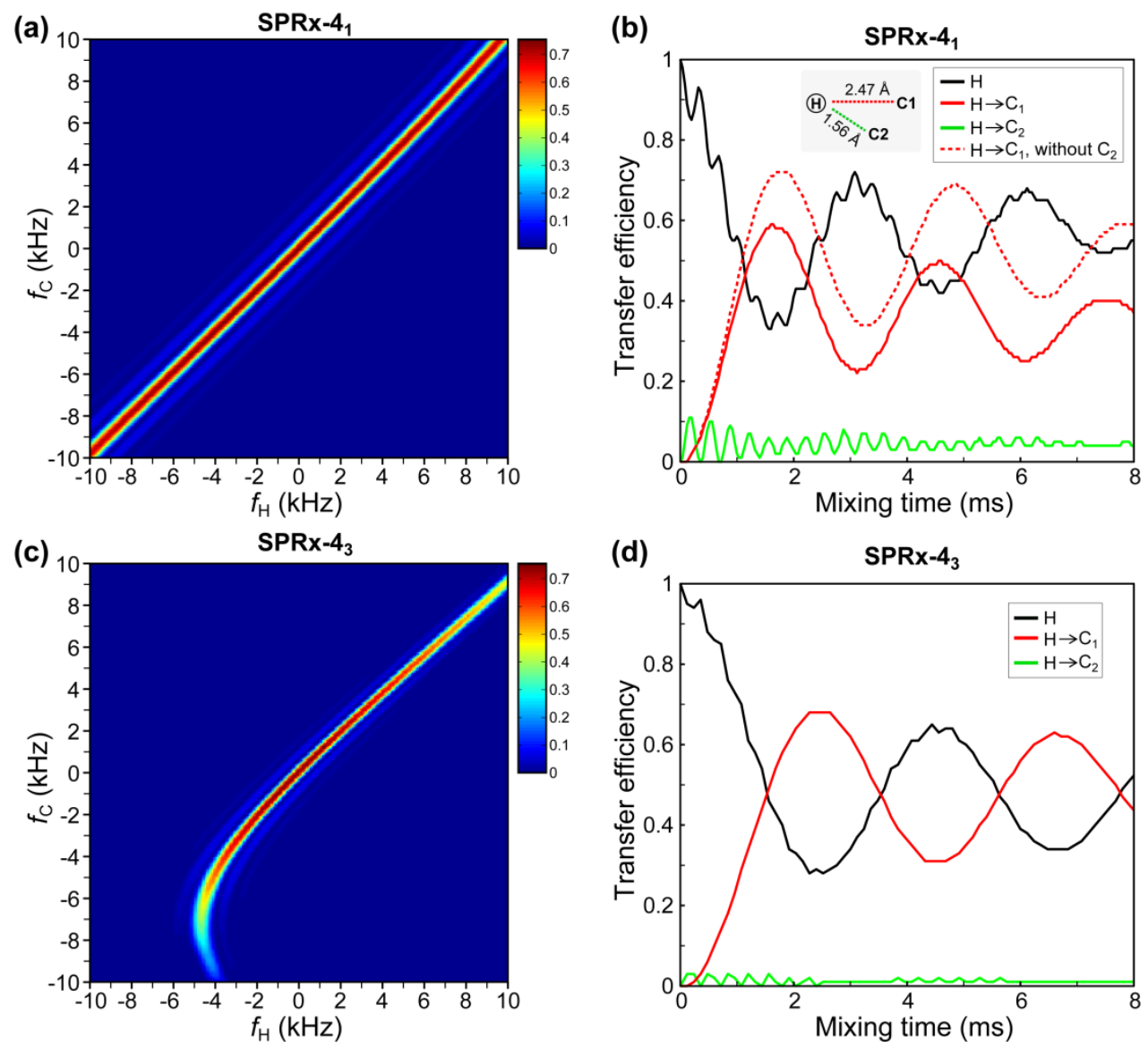

Figure 2 Simulated polarization transfer efficiency of $I_{z, \mathrm{H}} \rightarrow I_{\mathrm{z}, \mathrm{C}}$ as functions of frequency offsets (a, c) and mixing times (b, d) of SPRx $-4_{1}$ and SPRx- $4_{3}$ under $100 \mathrm{kHz}$ MAS. The RF amplitudes are $200 \mathrm{kHz}\left(2 v_{\mathrm{R}}\right)$ and $66.7 \mathrm{kHz}\left(0.667 v_{\mathrm{R}}\right)$ for SPRx$-4_{1}$ and SPRx$-4_{3}$, respectively. In $(\mathrm{a}, \mathrm{c})$, a two-spin system $\left({ }^{1} \mathrm{H},{ }^{13} \mathrm{C}\right)$ with the dipolar couplings of $2000 \mathrm{~Hz}$ is used. The $f_{\mathrm{H}}$ and $f_{\mathrm{C}}$ represent the frequency offsets of ${ }^{1} \mathrm{H}$ and ${ }^{13} \mathrm{C}_{1}$, respectively. The mixing times are 1.68 $\mathrm{ms}(m=42)$ and $2.4 \mathrm{~ms}(m=20)$ for SPRx $-4_{1}$ and SPRx $-4_{3}$, respectively. In $(\mathrm{b}, \mathrm{d}), \mathrm{a}$ three-spin system $\left({ }^{1} \mathrm{H},{ }^{13} \mathrm{C}_{1},{ }^{13} \mathrm{C}_{2}\right)$ is used in simulations, with the dipolar couplings of ${ }^{1} \mathrm{H}^{-13} \mathrm{C}_{1}$, ${ }^{1} \mathrm{H}_{-}{ }^{13} \mathrm{C}_{2}$, and ${ }^{13} \mathrm{C}_{1^{-}}{ }^{13} \mathrm{C}_{2}$ being $2000 \mathrm{~Hz}, 8000 \mathrm{~Hz}$, and $0 \mathrm{~Hz}$, respectively. $\left({ }^{1} \mathrm{H},{ }^{13} \mathrm{C}_{1}\right)$ is on resonance and ${ }^{13} \mathrm{C}_{2}$ is offset by $4 \mathrm{kHz}$. Simulations were performed under a magnetic field of ${ }^{1} \mathrm{H} 800 \mathrm{MHz}$ by using the SIMPSON software ${ }^{47}$.

Figure $2 \mathrm{a}$ and $\mathrm{b}$ show the simulated frequency-selectivity of SPRx$-4_{1}$ and $\operatorname{SPRx}-4_{3}$, respectively. Efficient transfer occurs with the frequency offsets along the diagonal, i.e. $f_{\mathrm{H}}=f_{\mathrm{C}}$, where $f_{\mathrm{H}}$ and $f_{\mathrm{C}}$ represent the frequency offsets for ${ }^{1} \mathrm{H}$ and ${ }^{13} \mathrm{C}$, respectively, with maximal efficiency of $\sim 0.73$ (b, dashed line). Efficient transfer can also be established along the anti-diagonal by using other super-cycled phases (Fig. S1). The different transfer profiles can provide flexibility to excite parts of nuclei in correlations.

With the $2 \mathrm{kHz}$ dipolar coupling, the bandwidths of SPRx$-4_{1}$ and SPRx$-4_{3}$ are $\sim 750 \mathrm{~Hz}$ 
and $\sim 520 \mathrm{~Hz}$, respectively (Fig. S2). Owing to the frequency-selectivity, the ${ }^{1} \mathrm{H}$ polarization can be selectively transferred to the weak-coupled ${ }^{13} \mathrm{C}_{1}$, although ${ }^{1} \mathrm{H}$ is strongly-coupled to ${ }^{13} \mathrm{C}_{2}$ (Fig. 2b, d). SPRx $-4_{3}$ provides a higher transfer efficiency of ${ }^{1} \mathrm{H} \rightarrow{ }^{13} \mathrm{C}_{1}(0.7)$ as it has better selectivity than $\mathrm{SPRx}-4_{1}$. It should be noted that the bandwidths in SPR are proportional to the dipolar coupling constants ${ }^{28}$. For this reason, the bandwidths of SPRx will be broader for stronger dipolar couplings, which are common for spin pairs such as ${ }^{1} \mathrm{H}^{19}{ }^{19} \mathrm{~F}$, ${ }^{1} \mathrm{H}-{ }^{13} \mathrm{C}$, and ${ }^{1} \mathrm{H}-{ }^{15} \mathrm{~N}$.

(a)
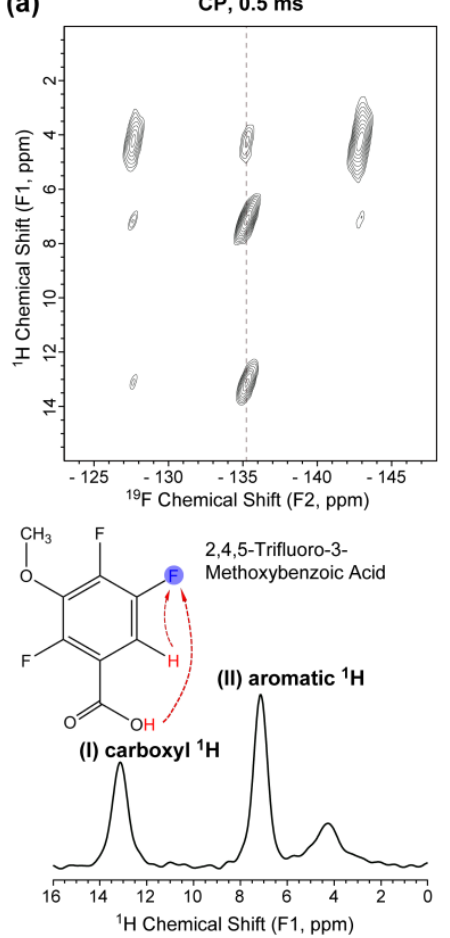

(b)
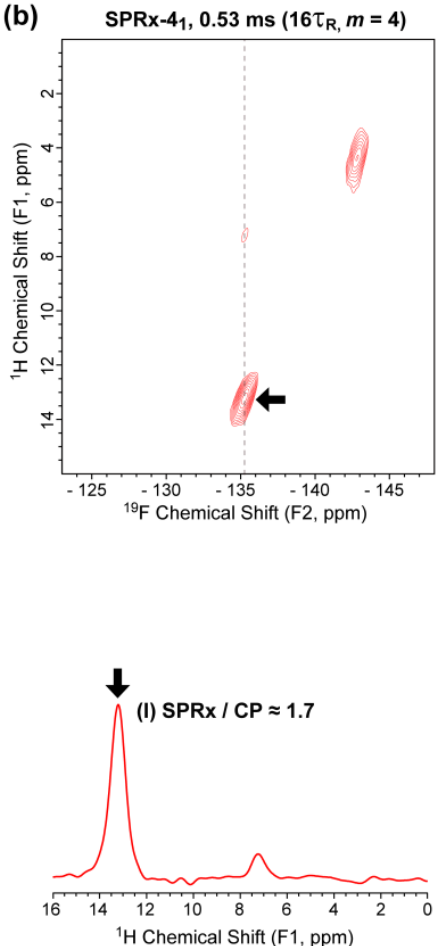

(c)
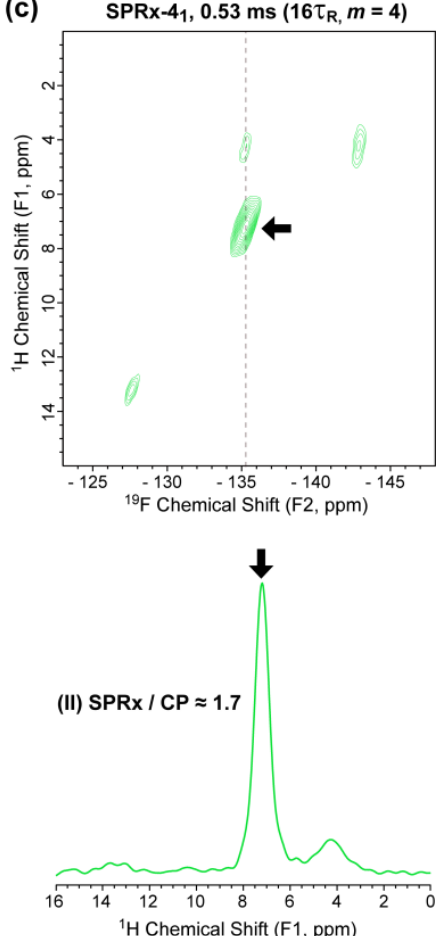

Figure 3 2D ${ }^{1} \mathrm{H}^{-19} \mathrm{~F}$ HETCOR (a) and FS-HETCOR (b, c) spectra (up) and 1D slices extracted along the dashed lines (bottom) of 2,4,5-trifluoro-3-methoxybenzoic acid (TMA) under $30 \mathrm{kHz}$ MAS. FS-HETCOR experiments were performed using the sequence in Fig. $1 \mathrm{~b}$. The RF amplitudes of SPRx -4 are $60 \mathrm{kHz}\left(2 v_{\mathrm{R}}\right)$ on both ${ }^{1} \mathrm{H}$ and ${ }^{19} \mathrm{~F}$. Red dashed arrows indicate the desired correlations in the molecular structure. Black arrows indicate the ${ }^{1} \mathrm{H}$ carrier transmitter during the SPRx- $4_{1}$ block $(b, c)$. The ${ }^{19} \mathrm{~F}$ carrier transmitter is set on $\mathrm{F}_{5}$ (-135.2 ppm, blue) for all the experiments. The ${ }^{1} \mathrm{H}$ Larmor frequency is $500 \mathrm{MHz}$.

The ${ }^{1} \mathrm{H}^{-19} \mathrm{~F}$ FS-HETCOR experiments were performed on 2,4,5-trifluoro-3-methoxybenzoic acid (TMA) under $30 \mathrm{kHz}$ MAS. SPRx- $4_{1}$ is used for selective ${ }^{1} \mathrm{H}^{-19} \mathrm{~F}$ polarization transfer as it can effectively overcome the interference from the relatively sizable ${ }^{19} \mathrm{~F}$ chemical shift anisotropy. Figure 3 a shows a regular $2 \mathrm{D}{ }^{1} \mathrm{H}-{ }^{19} \mathrm{~F}$ CP-based HETCOR spectrum, as a comparison. Since $\mathrm{CP}$ is non-selective, it is not surprising to observe multiple correlation peaks. Figure $3 \mathrm{~b}$ and $\mathrm{c}$ show the $2 \mathrm{D}{ }^{1} \mathrm{H}-{ }^{19} \mathrm{~F}$ FS-HETCOR spectra using SPRx $-4_{1}$. Due to the frequency-selectivity of SPRx- $4_{1}$, the correlation peaks between $\mathrm{F}_{5}$ and 
carboxyl ${ }^{1} \mathrm{H}$ (13.2 ppm, I) (b) and between $\mathrm{F}_{5}$ and aromatic ${ }^{1} \mathrm{H}$ (7.1 ppm, II) (c) are both selectively enhanced by a factor of $\sim 1.7$. A few minor correlation peaks such as (7.1 ppm, $-135.2 \mathrm{ppm}$ ) and (4.2 ppm, -135.2 ppm) (Fig. 2b and c) result from the transfer at the oscillating frequency (Fig. S2).
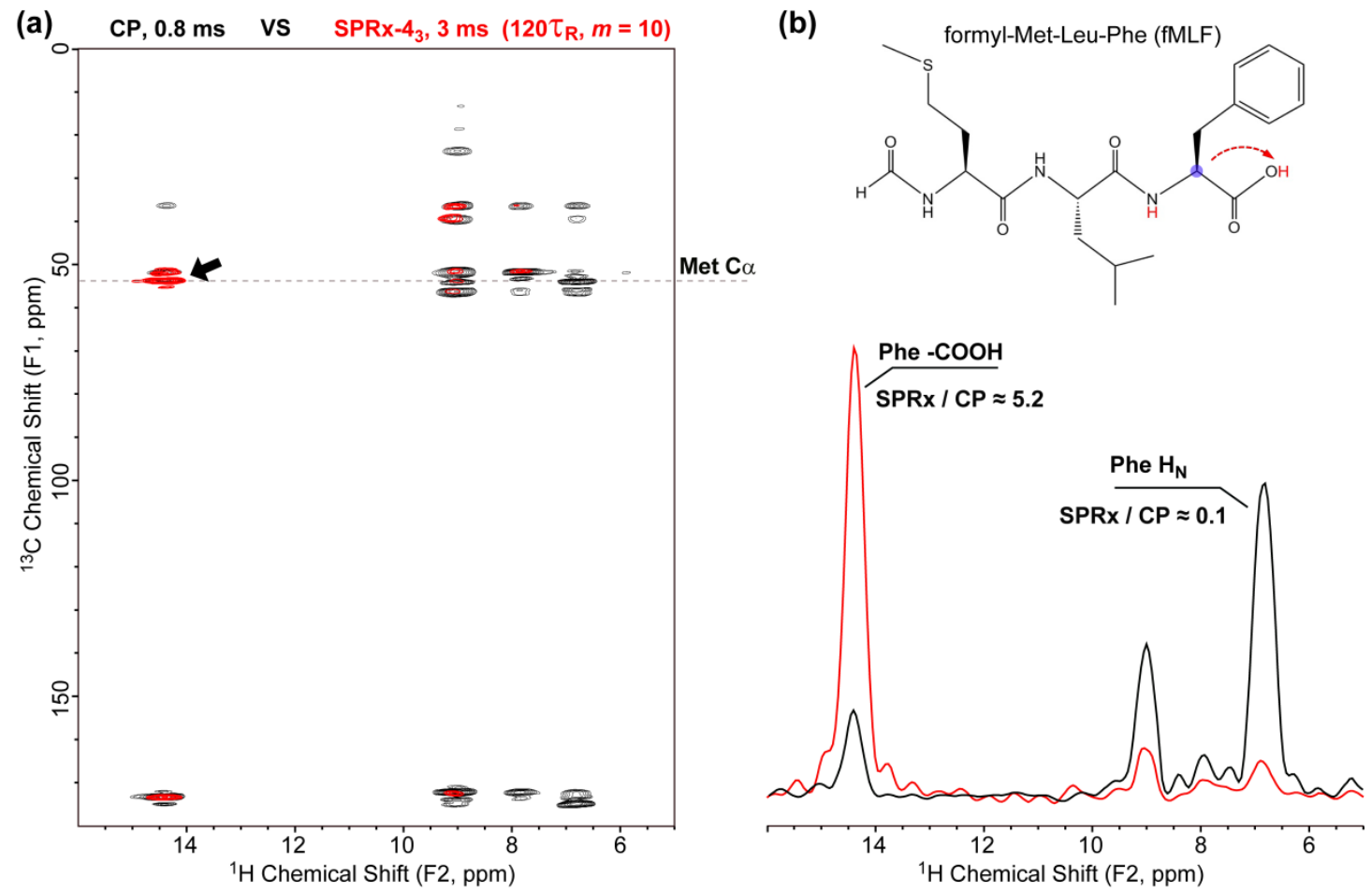

Figure 4 2D ${ }^{13} \mathrm{C}-{ }^{1} \mathrm{H}$ CP-HSQC (black) and FS-HETCOR (red) spectra (a) and 1D slices extracted along the dashed lines (b) of $\mathrm{U}_{-}{ }^{2} \mathrm{H},{ }^{13} \mathrm{C},{ }^{15} \mathrm{~N}$ labeled $\mathrm{N}$-formyl-Met-Leu-Phe (fMLF) under $40 \mathrm{kHz}$ MAS. The ${ }^{1} \mathrm{H}$-detected FS-HETCOR experiment is performed using the sequence in Fig. 1c. The RF amplitudes of $\mathrm{SPRx}-4_{3}$ are $26.7 \mathrm{kHz}\left(0.667 v_{\mathrm{R}}\right)$ on both ${ }^{1} \mathrm{H}$ and ${ }^{13} \mathrm{C}$. The black arrow indicates the desired correlation peak between carbonyl ${ }^{1} \mathrm{H}(14.4 \mathrm{ppm})$ and Phe ${ }^{13} \mathrm{C} \alpha$ (54.3 ppm) (a) and the red dashed arrow indicates its origin in the molecular structure. The ${ }^{1} \mathrm{H}$ carrier transmitter is set at $10.3 \mathrm{ppm}$ but moved to $14.4 \mathrm{ppm}$ (carbonyl ${ }^{1} \mathrm{H}$ ) during the SPRx $-4_{3}$ block. The ${ }^{13} \mathrm{C}$ carrier transmitter is set on Phe ${ }^{13} \mathrm{C} \alpha(54.3 \mathrm{ppm})$ for all the experiments. The ${ }^{1} \mathrm{H}$ Larmor frequency is $500 \mathrm{MHz}$.

The ${ }^{1} \mathrm{H}$-detected FS-HETCOR experiments were carried out on $\mathrm{U}_{-}^{2} \mathrm{H},{ }^{13} \mathrm{C},{ }^{15} \mathrm{~N}$ labeled $\mathrm{N}$-formyl-Met-Leu-Phe (fMLF) under $40 \mathrm{kHz}$ MAS. SPRx- $4_{3}$ is used for selective ${ }^{1} \mathrm{H}-{ }^{13} \mathrm{C}$ polarization transfer as it requires RF fields of $26.7 \mathrm{kHz}\left(0.667 v_{\mathrm{R}}\right)$. The low ${ }^{13} \mathrm{C} \mathrm{RF}$ field can be readily achieved on fast MAS probes, which are optimized for ${ }^{1} \mathrm{H}$ detection and typically bear lower ${ }^{13} \mathrm{C}$ RF fields than probes optimized for ${ }^{13} \mathrm{C}$ detection.

Figure 4 shows the $2 \mathrm{D}{ }^{13} \mathrm{C}-{ }^{1} \mathrm{H}$ CP-HSQC (black) and ${ }^{1} \mathrm{H}$-detected FS-HETCOR (red) spectra. The cross peak between carbonyl ${ }^{1} \mathrm{H}(14.4 \mathrm{ppm})$ and $\mathrm{Phe}{ }^{13} \mathrm{C} \alpha(54.3 \mathrm{ppm})$ is the 
correlation of interest as indicated by the arrow (Fig. 4a). In CP-HSQC, Phe ${ }^{13} \mathrm{C} \alpha$ is polarized mainly to the close Phe ${ }^{1} \mathrm{H}_{\mathrm{N}}\left(6.8 \mathrm{ppm}\right.$ ) but little to the remote Phe carboxylic ${ }^{1} \mathrm{H}$ (Fig. 4b, black). On the contrary, in the ${ }^{1} \mathrm{H}$-detected FS-HETCOR, by using the frequency-selectivity of SPRx $-4_{3}$, the desired correlation peak between Phe ${ }^{13} \mathrm{C} \alpha$ and the carboxylic ${ }^{1} \mathrm{H}$ is selectively enhanced by a factor of $\sim 5.2$. Meanwhile, the unwanted correlation peak between Phe ${ }^{13} \mathrm{C} \alpha$ and ${ }^{1} \mathrm{H}_{\mathrm{N}}$ is reduced to $10 \%$. The enhancement of peaks of interest and the reduction of unwanted ones clearly verify the efficacy of frequency-selectivity of SPRX- $N_{n}$.

It is worth noting that the SPRx- $4_{1}$ and $\mathrm{SPRx}-4_{3}$ are taken as examples to demonstrate their roles in FS-HETCOR experiments. They are demonstrated only under 30-40 kHz MAS restricted by our hardware capability. More representative $\mathrm{SPRx}-N_{n}$ are given in Table S2, which shall be applicable at arbitrary MAS rates, from relatively slow to ultrafast MAS. Besides, FS-HETCOR will benefit more from magnetic fields stronger than $11.25 \mathrm{~T}\left({ }^{1} \mathrm{H} 500\right.$ $\mathrm{MHz}$ ) used in this study, which increase the chemical shift dispersion in frequency units $(\mathrm{Hz})^{48-49}$.

\section{Conclusions}

In conclusion, we proposed novel FS-HETCOR experiments based on a new frequency-selective recoupling technique $\operatorname{SPRx}-N_{n}$, aiming to enhance the heteronuclear correlations of interest by utilizing their distinct resonance frequencies. The ${ }^{1} \mathrm{H}-{ }^{19} \mathrm{~F}$ and ${ }^{1} \mathrm{H}-{ }^{13} \mathrm{C}$ correlation experiments under $30-40 \mathrm{kHz}$ MAS demonstrate that, compared to regular CP-based HETCOR, FS-HETCOR can selectively enhance the desired heteronuclear correlations by a factor of up to 5 and suppress the unwanted ones to $10 \%$. It is thus anticipated to facilitate the observation of long-range correlations, which are usually truncated by short-range correlations in routine experiments. FS-HETCOR achieves the frequency-selectivity without any selective pulses and is extremely simple to set up. We believe that the method will enhance the ability of solid-state NMR to probe heteronuclear structural information. Future studies can be carried out in two directions. First of all, experiments with better frequency-selectivity can be performed on low- $\gamma 1 / 2$ spin pairs, e.g. ${ }^{13} \mathrm{C}-{ }^{15} \mathrm{~N},{ }^{13} \mathrm{C}-{ }^{31} \mathrm{P}$, and ${ }^{13} \mathrm{C}-{ }^{29} \mathrm{Si}$, which have weaker dipolar couplings than ${ }^{1} \mathrm{H}-{ }^{19} \mathrm{~F}$ and ${ }^{1} \mathrm{H}-{ }^{13} \mathrm{C}$ investigated in this study. Secondly, constant-time (CT) FS-HETCOR experiments can also be implemented following the means of homonuclear experiments ${ }^{30,50-52}$ so that heteronuclear distances can be measured quantitatively. Relevant work is underway.

\section{Conflict of interest}

The authors declare no conflict of interest.

\section{Acknowledgments}

This work was supported by grants from the National Natural Science Foundation of China (22074153, 21775161, 31770798, and 21927801), the National Key R\&D Program of China (2017YFA0505400), and the Chinese Academy of Sciences (to Z. Z. and J. Y.). We 
thank Dr. Mingyue Li for helping with preliminary experiments.

\section{References}

1. Maudsley, A. A.; Muller, L.; Ernst, R. R. Cross-Correlation of Spin-Decoupled NMR Spectra by Heteronuclear 2-Dimensional Spectroscopy. J. Magn. Reson. 1977, 28 (3), 463-469.

2. Bodenhausen, G.; Ruben, D. J. Natural Abundance N-15 NMR by Enhanced Heteronuclear Spectroscopy. Chem. Phys. Lett. 1980, 69 (1), 185-189.

3. Caravatti, P.; Bodenhausen, G.; Ernst, R. R. Heteronuclear Solid-state Correlation Spectroscopy. Chem. Phys. Lett. 1982, 89 (5), 363-367.

4. Cavadini, S.; Lupulescu, A.; Antonijevic, S.; Bodenhausen, G. Nitrogen-14 NMR spectroscopy using residual dipolar splittings in solids. J. Am. Chem. Soc. 2006, 128 (24), 7706-7707.

5. Gan, Z. Measuring amide nitrogen quadrupolar coupling by high-resolution N-14/C-13 NMR correlation under magic-angle spinning. J. Am. Chem. Soc. 2006, 128 (18), 6040-6041.

6. Hing, A. W.; Vega, S.; Schaefer, J. Transferred-echo double-resonance NMR. J. Magn. Reson. 1992, 96 (1), 205-209.

7. Michal, C. A.; Jelinski, L. W. REDOR 3D: Heteronuclear distance measurements in uniformly labeled and natural abundance solids. J. Am. Chem. Soc. 1997, 119 (38), 9059-9060.

8. Hong, M.; Griffin, R. G. Resonance assignments for solid peptides by dipolar-mediated C-13/N-15 correlation solid-state NMR. J. Am. Chem. Soc. 1998, 120 (28), 7113-7114.

9. Brinkmann, A.; Levitt, M. H. Symmetry principles in the nuclear magnetic resonance of spinning solids: Heteronuclear recoupling by generalized Hartmann-Hahn sequences. J. Chem. Phys. 2001, 115 (1), 357-384.

10. Jaroniec, C. P.; Filip, C.; Griffin, R. G. 3D TEDOR NMR experiments for the simultaneous measurement of multiple carbon-nitrogen distances in uniformly C-13, N-15-labeled solids. J. Am. Chem. Soc. 2002, 124 (36), 10728-10742.

11. Zhao, X.; Hoffbauer, W.; Gunne, J.; Levitt, M. H. Heteronuclear polarization transfer by symmetry-based recoupling sequences in solid-state NMR. Solid State Nucl. Magn. Reson. 2004, 26 (2), 57-64.

12. Brinkmann, A.; Kentgens, A. P. M. Proton-selective O-17-H-1 distance measurements in fast magic-angle-spinning solid-state NMR spectroscopy for the determination of hydrogen bond lengths. J. Am. Chem. Soc. 2006, 128 (46), 14758-14759.

13. Jain, S.; Bjerring, M.; Nielsen, N. C. Efficient and Robust Heteronuclear Cross-Polarization for High-Speed-Spinning Biological Solid-State NMR Spectroscopy. $J$. Phys. Chem. Lett. 2012, 3 (6), 703-708.

14. Zhang, Z. F.; Chen, Y. K.; Yang, J. Band-selective heteronuclear dipolar recoupling with 
dual back-to-back pulses in rotating solids. J. Magn. Reson. 2016, 272, 46-52.

15. Zhang, Z. F.; Li, J. P.; Chen, Y. K.; Xie, H. Y.; Yang, J. A robust heteronuclear dipolar recoupling method comparable to TEDOR for proteins in magic-angle spinning solid-state NMR. J. Magn. Reson. 2017, 285, 79-85.

16. Liang, L. X.; Ji, Y.; Zhao, Z. C.; Quinn, C. M.; Han, X. W.; Bao, X. H.; Polenova, T.; Hou, G. J. Accurate heteronuclear distance measurements at all magic-angle spinning frequencies in solid-state NMR spectroscopy. Chem. Sci. 2021, 12 (34), 11554-11564.

17. Nimerovsky, E.; Xue, K.; Movellan, K. T.; Andreas, L. B. Heteronuclear and homonuclear radio-frequency-driven recoupling. Magn. Reson. 2021, 2 (1), 343-353.

18. Pines, A.; Gibby, M. G.; Waugh, J. S. Proton-enhanced nmr of dilute spins in solids. $J$. Chem. Phys. 1973, 59 (2), 569-590.

19. Metz, G.; Wu, X. L.; Smith, S. O. Ramped-amplitude cross polarization in magic-angle spinning NMR. J. Magn. Reson. Ser. A 1994, 110 (2), 219-227.

20. Hediger, S.; Meier, B. H.; Ernst, R. R. Adiabatic passage Hartmann-Hahn cross polarization in NMR under magic angle sample spinning. Chem. Phys. Lett. 1995, 240 (5-6), 449-456.

21. Baldus, M.; Petkova, A. T.; Herzfeld, J.; Griffin, R. G. Cross polarization in the tilted frame: assignment and spectral simplification in heteronuclear spin systems. Mol. Phys. 1998, 95 (6), 1197-1207.

22. Laage, S.; Marchetti, A.; Sein, J.; Pierattelli, R.; Sass, H. J.; Grzesiek, S.; Lesage, A.; Pintacuda, G.; Emsley, L. Band-Selective H-1-C-13 Cross-Polarization in Fast Magic Angle Spinning Solid-State NMR Spectroscopy. J. Am. Chem. Soc. 2008, 130 (51), 17216-17217.

23. Demers, J. P.; Vijayan, V.; Becker, S.; Lange, A. Tailored low-power cross-polarization under fast magic-angle spinning. J. Magn. Reson. 2010, 205 (2), 216-223.

24. Reif, B.; Ashbrook, S. E.; Emsley, L.; Hong, M. Solid-state NMR spectroscopy. Nat. Rev. Methods Primers 2021, 1 (1), 2.

25. Lu, X. Y.; Skomski, D.; Thompson, K. C.; McNevin, M. J.; Xu, W.; Su, Y. Three-Dimensional NMR Spectroscopy of Fluorinated Pharmaceutical Solids under Ultrafast Magic Angle Spinning. Anal. Chem. 2019, 91 (9), 6217-6224.

26. Bayro, M. J.; Huber, M.; Ramachandran, R.; Davenport, T. C.; Meier, B. H.; Ernst, M.; Griffin, R. G. Dipolar truncation in magic-angle spinning NMR recoupling experiments. $J$. Chem. Phys. 2009, 130 (11), 114506.

27. Zhang, Z. F.; Oss, A.; Org, M. L.; Samoson, A.; Li, M. Y.; Tan, H.; Su, Y. C.; Yang, J. Selectively Enhanced H-1-H-1 Correlations in Proton-Detected Solid-State NMR under Ultrafast MAS Conditions. J. Phys. Chem. Lett. 2020, 11 (19), 8077-8083.

28. Xiao, H.; Zhang, Z. F.; Yang, J. Theory of frequency-selective homonuclear dipolar recoupling in solid-state NMR. J. Chem. Phys. 2021, 155 (17), 174105. 
29. Jain, M. G.; Lalli, D.; Stanek, J.; Gowda, C.; Prakash, S.; Schwarzer, T. S.; Schubeis, T.; Castiglione, K.; Andreas, L. B.; Madhu, P. K.; Pintacuda, G.; Agarwal, V. Selective H-1-H-1 Distance Restraints in Fully Protonated Proteins by Very Fast Magic-Angle Spinning Solid-State NMR. J. Phys. Chem. Lett. 2017, 8 (11), 2399-2405.

30. Duong, N. T.; Raran-Kurussi, S.; Nishiyama, Y.; Agarwal, V. Quantitative H-1-H-1 Distances in Protonated Solids by Frequency-Selective Recoupling at Fast Magic Angle Spinning NMR. J. Phys. Chem. Lett. 2018, 9 (20), 5948-5954.

31. Potnuru, L. R.; Duong, N. T.; Sasank, B.; Raran-Kurussi, S.; Nishiyama, Y.; Agarwal, V. Selective $1 \mathrm{H}-1 \mathrm{H}$ recoupling via symmetry sequences in fully protonated samples at fast magic angle spinning. J. Magn. Reson. 2021, 328, 107004-107004.

32. Bennett, A. E.; Becerra, L. R.; Griffin, R. G. Frequency-Selective Heteronuclear Recoupling in Rotating Solids. J. Chem. Phys. 1994, 100 (2), 812-814.

33. Traaseth, N. J.; Veglia, G. Frequency-selective heteronuclear dephasing and selective carbonyl labeling to deconvolute crowded spectra of membrane proteins by magic angle spinning NMR. J. Magn. Reson. 2011, 211 (1), 18-24.

34. Jaroniec, C. P.; Tounge, B. A.; Herzfeld, J.; Griffin, R. G. Frequency selective heteronuclear dipolar recoupling in rotating solids: Accurate $\mathrm{C}-13-\mathrm{N}-15$ distance measurements in uniformly C-13,N-15-labeled peptides. J. Am. Chem. Soc. 2001, 123 (15), 3507-3519.

35. Trebosc, J.; Amoureux, J. P.; Wiench, J. W.; Pruski, M. Simultaneous frequency-selective solid-state NMR analysis of internuclear distances and through-bond connectivities in the presence of quadrupolar nuclei. Chem. Phys. Lett. 2003, 374 (5-6), 432-438.

36. Bajaj, V. S.; Mak-Jurkauskas, M. L.; Belenky, M.; Herzfeld, J.; Griffin, R. G. DNP enhanced frequency-selective TEDOR experiments in bacteriorhodopsin. J. Magn. Reson. 2010, 202 (1), 9-13.

37. Bodenhausen, G.; Freeman, R.; Morris, G. A. Simple Pulse Sequence for Selective Excitation in Fourier-Transform NMR. J. Magn. Reson. 1976, 23 (1), 171-175.

38. Bauer, C.; Freeman, R.; Frenkiel, T.; Keeler, J.; Shaka, A. J. Gaussian Pulses. J. Magn. Reson. 1984, 58 (3), 442-457.

39. Emsley, L.; Bodenhausen, G. Gaussian Pulse Cascades - New Analytical Functions for Rectangular Selective Inversion and in-phase Excitation in NMR. Chem. Phys. Lett. 1990, 165 (6), 469-476.

40. Freeman, R. Shaped radiofrequency pulses in high resolution NMR. Prog. Nucl. Magn. Reson. Spectrosc. 1998, 32, 59-106.

41. Veshtort, M.; Griffin, R. G. High-performance selective excitation pulses for solid- and liquid-state NMR spectroscopy. Chemphyschem 2004, 5 (6), 834-850.

42. Ishii, Y.; Tycko, R. Sensitivity enhancement in solid state N-15 NMR by indirect 
detection with high-speed magic angle spinning. J. Magn. Reson. 2000, 142 (1), 199-204.

43. Ishii, Y.; Yesinowski, J. P.; Tycko, R. Sensitivity enhancement in solid-state C-13 NMR of synthetic polymers and biopolymers by H-1 NMR detection with high-speed magic angle spinning. J. Am. Chem. Soc. 2001, 123 (12), 2921-2922.

44. Chevelkov, V.; Rehbein, K.; Diehl, A.; Reif, B. Ultrahigh resolution in proton solid-state NMR spectroscopy at high levels of deuteration. Angew. Chem. Int. Ed. 2006, 45 (23), 3878-3881.

45. Zhou, D. H.; Shah, G.; Cormos, M.; Mullen, C.; Sandoz, D.; Rienstra, C. M. Proton-detected solid-state NMR Spectroscopy of fully protonated proteins at $40 \mathrm{kHz}$ magic-angle spinning. J. Am. Chem. Soc. 2007, 129 (38), 11791-11801.

46. Zhou, D. H.; Shea, J. J.; Nieuwkoop, A. J.; Franks, W. T.; Wylie, B. J.; Mullen, C.; Sandoz, D.; Rienstra, C. M. Solid-rate protein-structure determination with proton-detected triple-resonance 3D magic-angle-spinning NMR spectroscopy. Angew. Chem. Int. Ed. 2007, 46 (44), 8380-8383.

47. Bak, M.; Rasmussen, J. T.; Nielsen, N. C. SIMPSON: A general simulation program for solid-state NMR spectroscopy. J. Magn. Reson. 2000, 147 (2), 296-330.

48. Callon, M.; Malar, A. A.; Pfister, S.; Rimal, V.; Weber, M. E.; Wiegand, T.; Zehnder, J.; Chavez, M.; Cadalbert, R.; Deb, R.; Dapp, A.; Fogeron, M. L.; Hunkeler, A.; Lecoq, L.; Torosyan, A.; Zyla, D.; Glockshuber, R.; Jonas, S.; Nassal, M.; Ernst, M.; Bockmann, A.; Meier, B. H. Biomolecular solid-state NMR spectroscopy at $1200 \mathrm{MHz}$ : the gain in resolution. J. Biomol. NMR 2021, 75 (6-7), 255-272.

49. Nimerovsky, E.; Movellan, K. T.; Zhang, X. C.; Forster, M. C.; Najbauer, E.; Xue, K.; Dervisoglu, R.; Giller, K.; Griesinger, C.; Becker, S.; Andreas, L. B. Proton Detected Solid-State NMR of Membrane Proteins at 28 Tesla $(1.2 \mathrm{GHz})$ and $100 \mathrm{kHz}$ Magic-Angle Spinning. Biomolecules 2021, 11 (5), 18.

50. Paravastu, A. K.; Tycko, R. Frequency-selective homonuclear dipolar recoupling in solid state NMR. J. Chem. Phys. 2006, 124 (19), 194303.

51. Tycko, R. Symmetry-based constant-time homonuclear dipolar recoupling in solid state NMR. J. Chem. Phys. 2007, 126 (6), 064506.

52. Hu, K.-N.; Qiang, W.; Bermejo, G. A.; Schwieters, C. D.; Tycko, R. Restraints on backbone conformations in solid state NMR studies of uniformly labeled proteins from quantitative amide N-15-N-15 and carbonyl C-13-C-13 dipolar recoupling data. J. Magn. Reson. 2012, 218, 115-127. 